\title{
SOCIAL NETWORKING PLATFORMS AND HEALTH BEHAVIOUR OF STUDENTS: A STUDY OF WHATSAPP USAGE IN IGBINEDION UNIVERSITY OKADA
}

\author{
Ewomazino Daniel Akpor ${ }^{1}$, Muyiwa Adesuyi², Michael ILaya ${ }^{3}$, Mrs. Agidife-Philip Stella Oghenerobor ${ }^{4}$, \\ Sam Okeoghene Uyeri ${ }^{5}$ \\ E-Mail Id: akpor.ewomazino@edouniversity.edu.ng \\ ${ }^{1}$ Edo University, Iyamho, Nigeria \\ ${ }^{2}$ Igbinedion University, Okada, Nigeria \\ 3,4,5 Delta State Polytechnic, Ozoro, Nigeria
}

\begin{abstract}
Social media as a tool for rapid and effective communication has redefined the traditional communication tools such as; phone, computer, and the traditional media through the emergence of Social Networking sites (SNSs). SNSs like facebook, twitter, whatsapp, and others, are now in vogue targeting media audience and particularly patients with chronic conditions to change particular health risk behaviour. Researchers are now focusing on how to leverage on social influence to promote healthy behaviours. The fact that SNSs are widely accessible across geographical barriers and that they are increasingly being used by people on daily basis turn them into especially interesting place for public health interventions in the behavioural domain. Adopting the survey research, theories relevant to this study are the Social Cognitive, Technology Determinism and the Social Cognitive Theories. Using a sample size of 100, findings reveal that a large number of the students in Igbinedion University are aware of social networking sites and they use it often, the health messages received by the students are infrequent and that students do not believe all the health messages they received on social networking sites are true and most of the health messages are not credited to a source. The work concludes that health messages via SNSs have greater influence on people's health behaviour. The work recommends that the Federal Ministry of Health and Nigeria Communication Commission (NCC) under the auspices of the Ministry of Communication should monitor the flow of health messages on SNSs and that people should be sensitised on the need to take cognizance of health messages on SNSs and adhere to the instructions in order to verify the positive or negative effects of these health messages.
\end{abstract}

Keywords- Social Media, Health, Technology, Behaviour, Information.

\section{INTRODUCTION}

The widespread and use of modern Technology in communication no doubt turned the world into a Global village. The overwhelming benefits and influences of Information Communication Technology (ICT) on our way of life both socially and economically are quite enormous and far reaching.

Social networking site is used to describe any web site that enables users to create public profiles within that website and form relationships with other users of the same web site who access their profile. They include community-based websites, online discussion forum, chat rooms and other social spaces online. Term Social Networking Sites can be interchangeably used with Social Media or Social Networking Service.

Social networking sites (SNSs) have become a global phenomenon. They are generally defined as web-based platforms that allow individuals to create their own personal profile and build a network of connections with other users. As of September 2013, 73\% of online adults were using an SNS of some kind and 42\% were using more than one. Facebook is the most popular platform (with more than 1.19 billion monthly active users), followed by Twitter (500 million users worldwide) Liliana L, Amael A, Ana, N eta.1 (2014)

Social networking which is a fallout of social media has emerged as a powerful development tool, adding to the potency of mobile telecommunication as drivers of economic and democratic change, Ajisebiyawo (2016).

Millions of Nigerians daily visits or use Social Networking Sites include Facebook, Whatsapp, Instagram, Eskimi, Twitter, etc on daily basis to source for information, interact with online users and source for information that will affect their lives positively.

The realm of Social Networking Platforms is increasingly emerging as the subject of research in the field of social sciences. Students and lecturers from all academic spheres have begun to study the various aspects of Social Networking Sites.

Many investigations have been conducted around the world to unravel how these sites may influence issues of identity, privacy, social capital, youth culture, education and interpersonal relationships. Therefore, an attempt will be made in this chapter to review studies and articles related to the theme of the research. The review of literature allows us to study the main perspectives of similar studies conducted in the same field. This will give a proper guideline to the research work and enable integration of the past studies leading to the expansion of knowledge.

DOI Number: https://doi.org/10.30780/IJTRS.V05.I07.003

pg. 11

WWW.ijtrs.com

WWW.ijtrs.org 


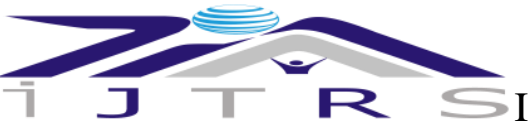

International Journal of Technical Research \& Science

Further review of literature has not only widened the horizon for understanding the themes related to the study, but also has sharpened the method of arranging the components in the framework of the study. This chapter is sub-divided into two sections to facilitate the emergence of a clear picture regarding the different dimensions of Social Networking Sites.

\section{STATEMENT OF THE PROBLEM}

Since the advent of social media sites in the 1990s, many people in Nigeria make health decisions without consulting a doctor or medical practitioner. Recently, People are exposed to and rely on health messages on social networking Platforms especially whatsapp, because most of these messages are sent by people they are familiar with and share abundant interpersonal relationship with.

Therefore the project is to examine the degree of influence social networking site whatsapp has on the health behaviour of students.

\section{RESEARCH QUESTIONS}

$>$ How often do IUO students use whatsapp?

$>$ How often do IUO students receive health messages via whatsapp?

$>$ How do IUO students perceive the whatsapp health messages they receive?

$>$ Has the use of whatsapp influenced IUO student's health behaviour?

\section{SCOPE OF THE STUDY}

The essence of this project is to primarily study the influence of social networking platforms specifically whatsapp on peoples' health behaviour.

The research intends to focus on Igbinedion University Okada (IUO) Students. The reason for this is to reduce cost and avoid complexity that may ensue as a result of having a very large population.

\section{LITERATURE REVIEW}

\subsection{Communication}

The term Communication was derived from a Latin word "Communicare" which means to share or establish commonness. Therefore, communication can be defined as the sharing of meaningful information, ideas, thoughts, opinion between individuals or among people. According to Little (1980) in Esimokha (2013), communication is the "process by which information is passed between individuals or organizations by means of previously agreed symbols". This definition emphasises that the sender and receiver must understand the language they intended to communicate.

Communication can be broadly categorised into two forms: verbal and Non-verbal where verbal communication is to communicate through words, it can be spoken or written while non-verbal is any form of communication that is not expressed in words, it includes: gestures, painting, drawing, signs, facial expression, etc. Communication can also be categorised into different types:

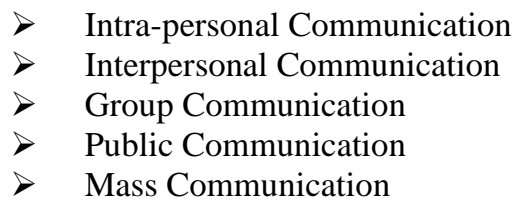

\subsection{Mass Communication}

Mass Communication is the process of using a medium to transmit information, ideas, attitudes, thoughts, expression and values to a large heterogeneous widely disperse and anonymous audience. Mass communication through the mass media has really shaped the communication process by distinguishing itself from other types of communication (interpersonal, intra-personal and group communication). Mass Communication employs the use of the media such as newspapers, magazines, books, television and the internet. The internet is the trending and widely use medium of mass communication because it can transmit messages rapidly to the audience than other media

\subsection{Mass Media}

The popular maxim that the mass media is regarded as the fourth estate of the realm is an ideal expression which implies that mass media is very important and influences a society's behaviour. According to Nwosu (1992), they are channels through which communication is addressed to a large heterogeneous and a cross section of the population. Mass media is a tool of mass communication used in sending across messages to a large and heterogeneous audience simultaneously. Mass media can be classified into print media and electronic media but the changes in technology generate the inclusion of the new media (Internet), although some scholars categorise 


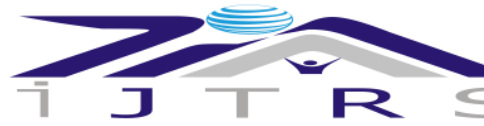

International Journal of Technical Research \& Science

the new media under electronic media. McQuail (1987) classified the mass media into seven namely: Print, pamphlet, newspaper; Recordings; Cinema; Radio; Television; Internet; Mobile phones, Functions of Mass Media.

The following are functions of the mass media

$>$ Inform

$>$ Surveillance

$>$ Hold society together

$>$ Entertain

$>$ Set the agenda

\subsection{Concept of Social Media}

Merriam Webster dictionary defined social media as forms of electronic communication (such as Web sites) through which people create online communities to share information, ideas, personal messages, etc. 1). Social media has become one of the major channels of chatting through platforms such as $2 \mathrm{go}$, BB chat, blogger and wiki a. There has been drastic increase in the mobile social media which has created new opportunity for browsing.

Kaplan and Haenlein (2010) classified social media into six different classes as follow:

$>$ Collaborative Project (Wikipedia)

$>\quad$ Blogs and Micro blogs (Twitter)

$>$ Content Communities ( $\mathrm{U}$-tube)

$>$ Social Networking Site (Facebook. 2go, whatsapp)

$>\quad$ Virtual Game World (World of war craft)

$>\quad$ Virtual Second World (Second life

\subsection{Studies on the Usage of Social Networking Sites among College Students}

Since the last decade, the usage of Social Networking Sites among college students has increased rapidly throughout the world. Evidently Social Networking Sites have become a significant part of the lives of these youths (Gemmill and Peterson: 2006). Students appear to be more aware than other groups, of the significance of social networking, mainly because they are attracted extensively to the new technology and particularly to the opportunity it offers for creating social networks.

Keol Lim and Ellen B Meier (2012) in their study clearly highlighted how and why Korean students use Social Networking Sites and what are the advantages they find by using Social Networking Sites. The study as such begins with the explanation of how the number of international students getting admission in U S universities has increased. It also refers to psychological experiences of international students such as disorientation, nostalgic depressive reactions, and feelings of isolation, alienation and powerlessness. However, international students may have limited ways to cope with stress, which could lead to stress-related illnesses such as anxiety or depression. Hence these limitations make it hard for international students to acclimatize themselves new circumstances.

Further, Keol and Meier (2012) mainly constrained themselves for only two research questions: How do these international students use Social Networking Sites? And how do these international students perceive the impact of Social Networking Sites on their affective and academic adaptation? This research was conducted in the United States with Asian international students, all from Korea, who were not raised in a western culture. Respondents in the study used Social Networking Sites in various ways and the tools played an important role in their adaptation to a new life in the United States. Findings of the study clearly showed that the respondents benefitted from their use of social networking sites and that the interactions helped to decrease their anxiety in the new culture by providing them with a means of connecting to their parents and friends in Korea. At the end it also stressed on the need of more research to identify the potential of Social Networking Sites in contributing to the affective and cognitive adaptation for international students including the connection between Internet use and academic achievement.

In a study entitled "Social capital as Facebook; differentiating uses and users" Burke and Marlow (2011) discussed extensively the perspective to look at the uses of Social Networking Sites. It says though usage of Social Networking Sites is often treated as a monolithic activity, in which all time is equally social and its impact the same for all users. The study primarily examines how Facebook affects social capital depending upon: types of site activities, contrasting one-on-one communication, broadcasts to wider audiences, and passive consumption of social news, and individual differences among users, including social communication skill and self esteem. In this study (2011) a survey was conducted using 415 Facebook users, which revealed that receiving messages from friends is associated with increase in bridging social capital. The major goal of the study was to observe how different uses of a large Social Networking Site influence different types of user's social capital. Social capital is the actual or potential resources which are linked to a durable network of more or less institutionalized relationships of mutual acquaintance or recognition. The study states that college students are motivated by social information-seeking, using Social Networking Sites to learn about people they have met offline, and expressive information sharking, feeling greater to bridge social capital. 


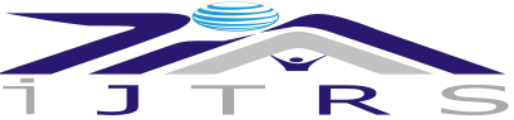

International Journal of Technical Research \& Science

Brandtzaeg and Jan (2009) in their study state that there are many motivational reasons for using Social Networking Sites among people and college students particularly. Brandtzaeg and Heim draw their findings, after the investigation on peoples' subjective motivational reasons for using Social Networking Sites, by performing a quantitative content analysis for 1,200 qualitative responses from Social Networking Sites users. Further, the study (2009) made several attempts to understand the choice, use, diffusion, adoption and acceptance of Social Networking Sites among college students.

Folorunso (2010) conducted a survey among students of the University of Agriculture, Abeokuta in Nigeria and tested the attributes of Diffusion of Innovations (DOI) theory towards usage pattern of Social Networking Sites. Demographic data of the study revealed that majority of users were college students. The five constructs i.e. Relative Advantage, Complexity, Compatibility, Observability and Reliability were used to test the impact on the attitude and trust regarding Social Networking Sites and to determine how attitude would impact on the intention to use it. The study revealed the constructs: relative advantage, complexity, and observability of Social Networking Sites do not positively affect the attitude towards using the technology while the compatibility and trial ability of Social Networking Sites does positively affect the attitude towards using the technology. The study (2010) concluded that the attitude of university students towards Social Networking Sites does positively affect the intention to use the technology.

\subsection{Health Behaviour}

Health Behaviour is any activity undertaken by an individual, regardless of actual or perceived health status, for the purpose of promoting, protecting or maintaining health, whether or not such behaviour is objectively effective towards that end.

It is possible to argue that almost every behaviour or activity by an individual has an impact on health status. In this context it is useful to distinguish between behaviours which are purposefully adopted to promote or protect health (as in the definition above), and those which may be adopted regardless of consequences to health. Health behaviours are distinguished from risk behaviours which are defined separately as behaviours associated with increased susceptibility to a specific cause of ill-health. Health behaviours and risk behaviours are often related in clusters in a more complex pattern of behaviours referred to as lifestyles.

\subsection{Studies on the Influence of Social Networking Sites on Health Behaviour Change}

Liiana Laranjo et al (2014) in their research work titled: The influence of social networking sites on health behaviour change: a systemic review and meta-analysis (2014), evaluated the use and effectiveness of interventions using social networking sites (SNSs) to change health behaviours. The result of their research shows that "Facebook" was the most utilized SNSs, followed by health specific SNSs, and Twitter. Eight randomized control trials were combined in a meta-analysis. A positive effect of SNSs intervention on health behaviour outcome was found, there was considerable heterogeneity.

Korda H, Itani Z. explored the need for using social media for health promotion and education in their scholarly work entitled: "Harnessing social media for health promotion and behaviour. Their findings show current evidence and understanding of using social media for health promotion. They further opined that it is necessary to evaluate the effectiveness of various forms of social media and incorporating outcome researches and theory in the design of health promotion programmes for social media.

Marel Salathe, Ph.d., Clark C.freifild, M.S.,[...], and John S Brownstein, PH.D. in their study examine Influenza (H7N9) and the importance of Digital Epidemology" gave insights into the importance of social networking sites for rapid dissemination of information. According to them, Digital Disease Surveillance has supplemented the critical laboratory and work in the trenches by public health officials and epidemiologist, by taking advantage of widespread use of internet, mobile phones and social media. It enabled the rapid flow of information about disease outbreak, availability of vaccines because in 2013 there are over 6.8billion cell phone subscribers; 2.7billion people are online. A large percentage of online subscribers share numerous information on social networking sites. They opined that digital data can be used in at least four ways for studying infectious-disease dynamics. Firstly, they can be used to detect outbreaks of disease in any part of the world because digital surveillance is not limited by hierarchies of traditional public health, geographical communication barriers, and geographical obstacles. For example, a hospital employee in China uploaded an image of the medical record of a patient with H7N9 infection to Sina Weibo (Chinese social network similar to twitter) made the government to acknowledge and affirm the situation.

Gunther Eysebach in his research entitled "infodemiology and infoveillance: framework for an emerging set of public health information methods to analyse, search, communication and publication behaviour on internet" ascertained that the internet has made measurable what was previously immeasurable: The distribution of health information in a population, tracking health information trends overtime and identifying gaps between information demand and supply. The paper also aims to illustrate the potential by suggesting applications for syndromic surveillance and management of public health emergencies, quality monitoring of information on the internet, knowledge translation, health communication, health marketing including collective behavioural measures at population level for public health policy and practice. 


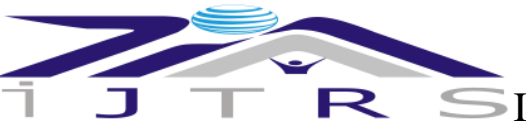

International Journal of Technical Research \& Science

A technical report on "Health communication and its role in the prevention and control of communicable diseases in Europe Current evidence, practice and future developments" by Dr. Jane Sixsmith, Ms Pricillia Doyle, MS Maureen D'Eath, Dr. S. Mahmood, Ms M. O'sullivan. This three-year research project funded by the European Centre for Disease Prevention and Control (ECDC) was undertaken by a Research Consortium of Universities. The result from the research formed the basis of a further level of stakeholder consultation. The aim of the consultation was to identify, from stakeholders' perspectives, what would be useful and practical to enhance and support future capacity and strategic development of health communication in the prevention and control of communicable diseases. The consultation was undertaken via an online asynchronous, private email consultation/mailing list: the ECDC-Health Communication Forum (ECDC-HCF). The questions posed covered the following domains: challenges, opportunities, feasibility, desirability and viability for the future development of health communication activities in EU/EEA countries over the next five years. Overall, results indicated varying levels of capacity for health communication in the prevention and control of communicable diseases within and between countries. Insights concerning the potential for capacity development were identified which included: enhanced sharing, coordination, collaboration, communication with key target audiences and stakeholders, development of stronger partnerships, and future use of new media. In addition, the role of evidence as a foundation for effective health communication developments and as a basis for building public trust was recognized, highlighting the need for the evidence base in Europe to be strengthened.

\section{THEORETICAL FRAMEWORK}

Two key theories are relevant to this study, they are:

\subsection{Social Cognitive Theory}

Social Cognitive Theory is founded in an agentic perspective. According to Albert Bandura, "This theory provides an agentic conceptual framework within which to analyse the determinants and psychosocial mechanism through which symbolic communication influences human thought, affect and action. Communication systems operate through two pathways. In the direct pathway, they promote changes by informing, enabling, motivating and guiding participants. In the socially mediated pathway, media influence link participants to social networks and community settings that provide natural incentives and continued personalised guidance, for desired change. Social cognitive theory analyses social diffusion of new styles of behaviour in terms of the psychological factors governing their acquisition and adoption and the social networks through which they spread and are supported".

\subsection{Technology Determinism Theory}

The term 'technological determinism' was coined by Thorstein Veblen. It is a reductionist theory that aims to provide a causative link between technology and a society's nature. The theory assumes that a society's technology determines the development of its social structure and cultural values. This theoretical framework is grounded in the fact that developmental changes in communication technology affect the society's decision on health behaviour positively or negatively.

\section{RESEARCH DESIGN}

The survey method was adopted for this work. The instrument of data collection was the questionnaire. The data was analysed with simple percentage.

\section{POPULATION OF THE STUDY}

The target population is the students of Igbinedion University Okada, Edo State. The Population is 2050 students according to information obtain from the Registrar's office.

\section{DATA ANALYSIS}

Table-9.1 Respondents Ownership of Social Media Equipment

\begin{tabular}{|c|c|c|}
\hline Variables & Frequency & Percent \\
\hline Phone & 44 & $44 \%$ \\
\hline Computer & 1 & $54 \%$ \\
\hline Both & 54 & $99 \%$ \\
\hline Total & 99 & $100 \%$ \\
\hline Missing & 1 & \\
\hline Total & 100 & $1 \%$ \\
\hline
\end{tabular}


] $\mathrm{E}$ International Journal of Technical Research \& Science

Table 9.1 shows that 44 students which accounts for $44 \%$ of the total respondents own phone only, 1 (1\%) respondent own computer only while 54(54\%) own both computer and phone. This indicates that more than half of the respondents have both phone and computer.

Table-9.2 Distribution of Responses on Access to Internet

\begin{tabular}{|c|c|c|}
\hline Variable & Frequency & Percentage \\
\hline Yes & 97 & $97 \%$ \\
\hline No & 3 & $3 \%$ \\
\hline Total & 100 & $100 \%$ \\
\hline
\end{tabular}

Field Survey 2019

$97 \%$ respondents making $97 \%$ of the total sample size admits that they have access to internet, $3(3 \%)$ admits that they do not have any access to the internet.

Table-9.3 Distribution of Responses on Awareness of Whatsapp Social Networking Site

\begin{tabular}{|c|c|c|}
\hline Variable & Frequency & Percentage \\
\hline Yes & 99 & $99 \%$ \\
\hline No & 1 & $1 \%$ \\
\hline Total & 100 & $100 \%$ \\
\hline
\end{tabular}

Field Survey 2019

The table above shows that 99 respondents making a total of $99 \%$ indicated being aware of whatsapp social networking site, only a percent $(1 \%)$ making 1 respondent indicated not being aware of whatsapp.

\begin{tabular}{|c|c|c|}
\hline \multicolumn{2}{|c|}{ Table-9.4 Distribution of Responses on Usage of Whatsapp } \\
\hline Variable & Frequency & Percentage \\
\hline Yes & 94 & $64 \%$ \\
\hline No & 6 & $100 \%$ \\
\hline Total & 100 & $6 \%$ \\
\hline
\end{tabular}

Field Survey 2019

From the above table, 94 respondents making $94 \%$ of the total sample size use whatsapp social networking sites while 6 respondents which is $6 \%$ do not use whatsapp.

Table-9.5 Distribution of Responses on How Often Respondents Use Whatsapp

\begin{tabular}{|c|c|c|}
\hline Variable & Frequency & Percentage \\
\hline Very Often & 45 & $45 \%$ \\
\hline Often & 29 & $29 \%$ \\
\hline Sometimes & 20 & $1 \%$ \\
\hline Rarely & 1 & $3 \%$ \\
\hline Never & 3 & $100 \%$ \\
\hline Total & 100 & \\
\hline
\end{tabular}

Field Survey 2019

Fourty-five(45) respondents (45\%) admit that they go online on whatsapp very often, 29 respondents (29\%) admits that they use whatsapp often, 20 respondents making $20 \%$ indicates that they do not use whatsapp always but sometimes, 1 respondent rarely use whatsapp while 3 respondents (3\%) never used whatsapp. This shows that majority of the respondents use whatsapp.

Table-9.6 Distribution of Responses on Recipient of Health Messages on Whatsapp

\begin{tabular}{|c|c|c|}
\hline Variable & Frequency & Percentage \\
\hline Yes & 73 & $73 \%$ \\
\hline No & 15 & $15 \%$ \\
\hline Not Sure & 9 & $9 \%$ \\
\hline
\end{tabular}

DOI Number: https://doi.org/10.30780/IJTRS.V05.I07.003

pg. 16

WWW.ijtrs.com

WWW.ijtrs.org

Paper Id: IJTRS-V5-I4-014

Volume V Issue VII, July 2020 @ 2017, IJTRS All Right Reserved 


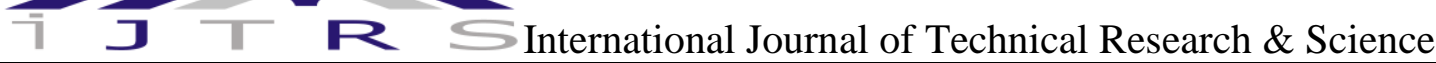

\begin{tabular}{|c|c|c|}
\hline Missing & 3 & $3 \%$ \\
\hline Total & 100 & $100 \%$ \\
\hline
\end{tabular}

Field Survey 2019

Table 6 shows that 73 respondents making $73 \%$ of the sampled population receives health related messages on whatsapp, 15(15\%) of the respondents do not receive health messages, while 9 respondents making $9 \%$ are not sure if they receive health messages or not and $3(3 \%)$ do not give their opinion on this. This indicates that majority of the respondents are in a position to provide informed response on the subject matter.

Table -9.7 Distribution of Responses on how often do Respondents Receive Health Messages on Whatsapp

\begin{tabular}{|c|c|c|}
\hline Variable & Frequency & Percentage \\
\hline Very Often & 9 & $9 \%$ \\
\hline Often & 23 & $40 \%$ \\
\hline Sometimes & 40 & $18 \%$ \\
\hline Rarely & 18 & $8 \%$ \\
\hline Never & 8 & $2 \%$ \\
\hline Missing & 2 & $100 \%$ \\
\hline Total & 100 & \\
\hline
\end{tabular}

Field Survey 2019

Table 9.7 shows that the entire sampled size do not really receive health messages on whatsapp as $40 \%$ making 40 respondents indicated they receive health messages sometimes, 18(18\%) indicated they rarely receive health messages, $8(8 \%)$ indicated not to have ever received health messages, $2 \%$ making 2 respondents did not give their opinion while 9 respondents making $9 \%$ indicated they receive health related messages very often and $23 \%$ making 23 respondents indicated that they often receive health messages.

Table-9.8 Distribution of Responses on Whether Respondents Believe the Health Messages Received are True

\begin{tabular}{|c|c|c|}
\hline Variable & Frequency & Percentage \\
\hline Yes & 35 & $35 \%$ \\
\hline No & 12 & $12 \%$ \\
\hline Not All & 49 & $49 \%$ \\
\hline Missing & 4 & $100 \%$ \\
\hline Total & 100 & $4 \%$ \\
\hline
\end{tabular}

Table 9.8 shows that a just a percent below half (49\%) of the total sample size making up 49 respondents believes that not all the health messages on whatsapp are true, 35(35\%) holds that all the health messages they received on via whatsapp are true, 12 respondents making $12 \%$ of th e sampled population indicated that the health messages via whatsapp are not true while, $4(4 \%)$ respondents are indecisive.

Table 9.9 Distribution of Response on Whether the Health Messages are Credited to a Source

\begin{tabular}{|c|c|c|}
\hline Variable & Frequency & Percentage \\
\hline Yes & 28 & $28 \%$ \\
\hline No & 16 & $16 \%$ \\
\hline Not All & 52 & $52 \%$ \\
\hline Missing & 4 & $4 \%$ \\
\hline Total & 100 & $100 \%$ \\
\hline
\end{tabular}

Field Survey 2019

Table 9.9 shows that 52 respondents making more than 50 percent of the sampled size indicated that not all the health messages received via whatsapp are credited to a source, $16(16 \%)$ indicated that none of the health 


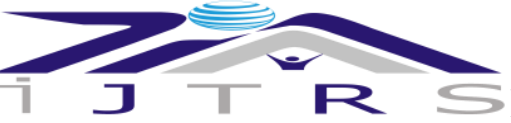

International Journal of Technical Research \& Science

messages are credited to a source, $28(28 \%)$ respondents indicated that all the health messages they received via whatsapp are gives credit to the source while $4(4 \%)$ did not give opinion on this question.

Table-9.10 Distribution of Responses on Whether Health Messages on Whatsapp has Influence on People's Health Behaviour

\begin{tabular}{|c|c|c|}
\hline Variable & Frequency & Percentage \\
\hline Strongly Agree & 16 & $16 \%$ \\
\hline Agree & 58 & $19 \%$ \\
\hline Disagree & 19 & $4 \%$ \\
\hline Strongly Disagree & 4 & $3 \%$ \\
\hline Missing & 3 & $100 \%$ \\
\hline Total & 100 & \\
\hline
\end{tabular}

Field Survey 2019

Table 9.10 shows that majority of the respondents agreed health messages on whatsapp influences people's health behaviour as 16(16\%) respondents strongly agreed, $58(58 \%)$ respondents making more than half of the sampled population agreed while, 19(19\%) respondents disagree, 3(3\%) strongly disagree and 3(3\%) are indecisive.

Table-9.11 Distribution of Responses on how Health Messages on Whatsapp has Influenced Respondents Health Behaviour

\begin{tabular}{|c|c|c|}
\hline Variable & Frequency & Percentage \\
\hline Positively & 49 & $49 \%$ \\
\hline Negatively & 2 & $47 \%$ \\
\hline No Response & 47 & $2 \%$ \\
\hline Missing & 2 & $100 \%$ \\
\hline Total & 100 & \\
\hline
\end{tabular}

Field Survey 2019

Table 9.11 shows that 49 respondents making $49 \%$ indicated that health messages on whatsapp had positive effects on their health, $2(2 \%)$ respondents opined that these health messages had negative effects on their health, $47(47 \%)$ respondents said no response, While $2(2 \%)$ did not give their opinion.

\section{DISCUSSION OF FINDINGS}

Research Question 1: How often do IUO students use whatsapp?

Table 9.3, 9.4 and 9.55 shows that students in Igbinedion University Okada are aware of whatsapp and they use whatsapp very often. This further indicated that the respondents spend a lot of time online on whatsapp. This finding agrees with Gemmil and Peterson (2006) position that "Evidently Social Networking Sites have become a significant part of the lives of these youth" since they are aware of these sites and use them often.

Research Question 2: How often do IUO students receive health messages via whatsapp?

Table 9.6 and 9.7 vividly answers this question. Table 9.11 shows that majority of the respondents receive health related messages via whatsapp while table 9.10 indicated that the respondents do not receive health messages often but sometimes. This finding is supported by Marel Salathe, Ph.d., Clark C.freifild, M.S.,[...], and John S Brownstein, PH.D. They examined "Influenza (H7N9) and the importance of Digital Epidemology". According to them, Digital Disease Surveillance has supplemented the critical laboratory and work in the trenches by public health officials and epidemiologist, by taking advantage of widespread use of internet, mobile phones and social media.

Research Question 3: How do IUO students perceive the whatsapp health messages they receive?

Table 9.8 and 9.9 help to show how the respondents perceive the health messages they receive via whatsapp. Table 9.11 shows that the respondents do not believe all the health messages via whatsapp are true. Table 9.9 shows that majority of the respondents sees that the health messages on whatsapp are not credited to a source. People are shaped by what they believe in and will not follow instructions they do not believe. This indicates that it will be difficult for people to adhere to instructions they do not believe.

Research Question 4: Has the use of whatsapp influenced IUO student's health behaviour?

DOI Number: https://doi.org/10.30780/IJTRS.V05.I07.003

pg. 18

www.ijtrs.com

www.ijtrs.org 


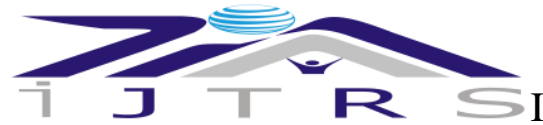

International Journal of Technical Research \& Science

Table 9.10 and 9.11 buttress the point whatsapp is a social tool that influence health behaviour, this is because majority of the respondents agreed that health messages on whatsapp has influence on people's health behaviour. And the respondents in table 9.11 shows that whatsapp has a positive influence than a negative one on their behaviour. The respondents that gave no response proves that some of the respondents do not take heed to the health messages they receive so they could not discern if the effect of the health messages are positive or negative. In 2014, Liiana Laranjo, Amael Arguel, and Annie Y S Lau in their research work titled: "The influence of social networking sites on health behaviour change: a systematic review and meta-analysis" evaluated the use and effectiveness of interventions using social networking sites to change health behaviours. Their findings showed that SNSs interventions on health behaviours have a positive effect.

\section{SUMMARY OF FINDINGS}

The findings showed that:

$>$ A large number of the students in Igbinedion University are aware of whatsapp social networking site and they use it often.

$>\quad$ The health messages received by the students are infrequent.

$>$ The students do not believe all the health messages they received on whatsapp are true and most of the health messages are not credited to a source.

$>\quad$ The health messages via whatsapp have influence on people's health behaviour but a large number of the students did not give response if these messages have influenced them positively or negatively. It is therefore assumed that those who gave no response did not take into consideration the instructions in the messages they received.

\section{CONCLUSION}

The adoption of the new media as a vehicle of rapid dissemination of information cannot be over emphasised. This study has further proved that the new media function is not limited to exchange of information alone but act as a channel that improves our well being. Today, anyone who is not technologically inclined will not be cognizant of new trends in every spheres of social life. Technology has redefined the way we interact with one and other and it is the catalyst for the advancements and seen developments in all sectors in the world especially the health sector.

Health status of members of the society is very crucial to survival of the society so if people ignore health interventions on Social Networking sites (SNSs) or receive misleading health related messages, it can have negative effects on their health behaviour.

Students in Igbinedion University Okada and Nigerian Universities at large are aware of whatsapp social networking and they receive health related messages sometimes via whatsapp. The health interventions on social networking sites especially whatsapp are not many, therefore the health sector in Nigeria is not utilising the super informative function of the new media. This means that the health campaigns in Nigeria are not up mostly channelled by social networking sites. Health interventions via whatsapp have a positive influence on people's health behaviour but most Nigerians ignore the instructions embedded in the health messages.

\section{RECOMMENDATIONS}

The following are recommendations to improve people's perception of health-related messages on whatsapp and to ensure the adherence of whatsapp users or social media users to the received health interventions in order to maintain, improve health status and prevent health risk.

$>\quad$ The Federal ministry of Health and Nigeria Communication Commission (NCC) under the auspice of the Ministry of Communication should monitor the flow of health messages on whatsapp and other social media platforms.

$>\quad$ The Nigerian populace should be sensitised on the need to take cognizance of health messages on whatsapp and adhere to the instructions thereof in order to verify the positive or negative effects of these health messages.

$>$ NCC should make policies that will ensure health messages are not uploaded on social media without being credited to a source.

$>\quad$ There is need for wider consultation, partnership and collaboration with various health associations either governmental or non- governmental, private and public, etc

$>$ Owing to the fact that technology is changing the way we think and make decisions, mass media campaign in the health sector via whatsapp and other social media platforms should be encouraged.

\section{REFERENCES}

[1] Adreas M. Michael H. (2010), Challenges and opportunities of Social media. Business horizons, ESCP Europe.

[2] Andrew, I. (2005) Reading in mass communication and Nigeria Satellite. Makurdi: Benue State University

DOI Number: https://doi.org/10.30780/IJTRS.V05.I07.003

pg. 19

WWW.ijtrs.com

wWw.ijtrs.org

Paper Id: IJTRS-V5-I4-014

Volume V Issue VII, July 2020 @ 2017, IJTRS All Right Reserved 
7 $\longrightarrow$ \& International Journal of Technical Research \& Science

[3] Ajisebiyawo, K (2016) Social Media and Democracy, in Okwilagwe O. A and Elebute, A (Ed) Issues in Mass Media, Communication Studies and Research in Nigeria, Ibadan, Stirling-Horden Publishers Ltd.

[4] Barry M, Vinton C. et al (1997). A brief history of internet and related networks. Internet society Switzerland.

[5] Esimokha G, (2013) English for Mass Communication. A systemic Guide on Writing Skills. Offa: Dalaz Prints

[6] Folorunsho, Olusegun, (2010), Diffusions of Innovation in Social Networking Sites among University Students. International Journal of Computer Science and Security.

[7] Gemmil, E and Peterson, M. (2006), Technology Use Among College Students: Implications for Students Affairs Professionals. NAPSA Journal.

[8] Gunther E. (2009), Infodemiology and Infoveillance: Framework from an Emerging sets of public informatics methods to analyse search, communication and Publication Behaviour on the internet: Journal of Medical Internet Research.

[9] Korda H., Itani z. (2011) Harnessing Social Media for Health Promotion and Change. Altarum Institute Portland, ME, USA.

[10] Keol, Lim and Ellen, B. Meier, (2012) International Student's Use of Social Network Services in the New Culture. A case study with Korean Youths in the United States. Asia Pacific Educ. Review

[11] Liana L, et al, (2014) The influence of social networking sites on health behaviour change: a systemic review and meta-analysis, American Medical Informatics Association Review, Oxford University Press.

[12] McBurney H. B. (1993) Research Methods. Wadsworth Cenage Learning.

[13] McQuail, D. (1987) Mass Communication Theory: An Introduction. Sage Publication Language Arts Discipline

[14] Nworgu, B.G. (1991) Educational Research: Basic issues and Methodology. Ibadan: Wisdom Publishers ltd.

[15] Okafor, Godson (2002) in C.S. Okunna (2002) Teaching Mass Communication: A Multi-Dimensional Approach. Enugu: New Generation Books

[16] Okoro, M. N. (2001) Mass Communication Research: Issues and Methodologies. Nsukka: AP Express Publishers.

[17] Petter, Bae Brandtzaeg and Jan, Heim. 2009. "Why People Use Social Networking Sites”. Springer. Verlag Berlin Heidelberg.

[18] Rhee, K. and Kim W (2004) The Adoption and the use of the Internet in South Korea. Journal of Computer Mediated Communication

[19] Salathe, M. et all, (2013), Influenza (H7N9) and the importance of Digital Epidemology. N Engl med; 369 : 401- 404

[20] Wimmer, D. R. and Dominick, J. R. (2003) Mass Media Research (7 ${ }^{\text {th }}$ Ed.) Belmont: Wadsworth/Thompson Learning Inc. 